\title{
Quality of life of chronic kidney patients on hemodialysis and related factors*
}

\author{
Carolina Renz Pretto ${ }^{1}$ \\ (1) https://orcid.org/0000-0002-6925-7969 \\ Eliane Roseli Winkelmann ${ }^{1}$ \\ (1D) https://orcid.org/0000-0002-4922-6516 \\ Leila Mariza Hildebrandt² \\ (1) https://orcid.org/0000-0003-0504-6166 \\ Dulce Aparecida Barbosa ${ }^{3}$ \\ (D) https://orcid.org/0000-0002-9912-4446 \\ Christiane de Fátima Colet ${ }^{1}$ \\ (1) https://orcid.org/0000-0003-2023-5088 \\ Eniva Miladi Fernandes Stumm ${ }^{1}$ \\ (iD) https://orcid.org/0000-0001-6169-0453
}

Objective: to verify the association between the healthrelated quality of life of chronic renal patients on hemodialysis with sociodemographic, clinical, depression and medication adherence characteristics. Method: a cross-sectional study with 183 chronic renal patients undergoing hemodialysis in the state of Rio Grande do Sul, Brazil. A sociodemographic and clinical questionnaire, Kidney Disease and Quality of Life Short-Form, Beck Depression Inventory and Morisky Medication Adherence Scale - eight items were used. Among the variables, comorbidities, complications of kidney disease and intercurrences during and after hemodialysis were evaluated. The analysis was performed with descriptive and analytical statistics. Results: $55.2 \%$ of the patients were 60 years old or older, $35.0 \%$ were hypertensive, with regular quality of life, average of 62.61. Scores below average in the dimensions of quality of life were mainly associated with repetitive infections and edema as complications of the disease, pain during hemodialysis and weakness afterwards. Low drug adherence resulted in a worse quality of life, impacting ten of the 20 dimensions evaluated and depression in all, except for patient satisfaction. Conclusion: reduced quality of life in this population is associated with depressive symptoms, complications such as repetitive infections, pain and anemia, weakness after the dialysis session and low medication adherence. Actions aimed at changing these factors can promote well-being.

Descriptors: Quality of Life; Depression; Nursing; Signs and Symptoms; Renal Insufficiency, Chronic; Medication Adherence.

\section{How to cite this article}

Pretto CR, Winkelmann ER, Hildebrandt LM, Barbosa DA, Colet CF, Stumm EMF. Quality of life of chronic kidney patients on hemodialysis and related factors. Rev. Latino-Am. Enfermagem. 2020;28:e3327. [Access _ f _ ]; Available in: DOI: http://dx.doi.org/10.1590/1518-8345.3641.3327. 


\section{Introduction}

The number of deaths caused by Chronic Kidney Disease (CKD) is increasing worldwide and, in 2017, $1,230.2$ million people $\operatorname{died}^{(1)}$. In Brazil, in the same year, the number of deaths of patients on dialysis was estimated at 25,187 deaths, which represented a gross mortality rate of $19.9 \%$. In the country, to ensure survival and treatment of patients, the number of active dialysis centers has increased and, among the modalities of renal replacement therapies offered, hemodialysis is predominant. In $2017,93.1 \%$ of the patients were on this therapy ${ }^{(2)}$.

CKD is characterized by decreased renal function, explained by a glomerular filtration rate of less than $60 \mathrm{ml} / \mathrm{min} / 1.73 \mathrm{~m}^{2}$ and/or markers of renal damage lasting three months or more ${ }^{(3)}$. Progressively, it becomes a metabolic and endocrine problem that triggers inflammation and compromises immune capacity. Patients affected by this disease have low socioeconomic conditions, a high risk of morbidity, mortality and lower Health-Related Quality of Life - HRQoL (3-5).

HRQoL is the subject's perception in relation to his position in life, cultural environment and values in which he is inserted, objectives, expectations, standards and concerns. It is related to physical health, mental state, independence, social relationships, beliefs and peculiarities of the environment( ${ }^{(6)}$. So, it comprises effects of the disease and/or treatment in the diverse life dimensions.

Psychosocial and biological changes related to dialysis treatment increase the risk of developing depression in patients with CKD. It is estimated that this population has rates of this disorder being three to four times higher than the general population and two to three times higher than in individuals with other chronic diseases. Depression also increases the risk of progression of kidney disease, worse clinical outcomes and mortality ${ }^{(7)}$.

Although the relationship between depression and HRQoL in CKD is well established ${ }^{(8-9)}$, it can be deepened with respect to the commitment of each domain that integrates it. Studies with chronic renal patients undergoing hemodialysis have also shown an association between quality of life, sociodemographic characteristics(10-12) $^{(12}$ comorbidities ${ }^{(13)}$. Regarding the relationship with complications of kidney disease, few studies have attempted to identify $i^{(14)}$ or assess association with specific complications, such as pain ${ }^{(15)}$ and anemia(16).

With regard to intercurrences during hemodialysis, investigations show, however, that they do not stop to explore their connection with HRQoL ${ }^{(17-18)}$. No specific studies on intercurrences were found after the end of the hemodialysis session and few were identified with general approaches on the symptoms ${ }^{(19-20)}$. Regarding adherence to drug therapy, there are few publications on the subject in this population that analyze the relationship with quality of life $\mathrm{e}^{(21)}$.

In view of the aforementioned, there is a lack of knowledge regarding the association between HRQoL with complications of kidney disease, intercurrences during and after hemodialysis and adherence to drug therapy in chronic renal patients. Thus, this study aims to verify the association between the health-related quality of life of chronic renal patients on hemodialysis with sociodemographic, clinical, depression and medication adherence characteristics.

\section{Method}

This is an exploratory, cross-sectional and analytical research, with a quantitative approach, developed from February to October 2017 in two renal units in Rio Grande do Sul, Brazil. One is a reference for the Northwest region, which integrates a philanthropic health care institution, and the other, a reference for the Missions region, a private administration clinic, for profit, but with greater demand from patients in the Unified Health System (Sistema Único de Saúde - SUS - in Portuguese).

The study population comprised 238 patients registered in the two units. Of these, 183 over 18 years old diagnosed with CKD and undergoing hemodialysis were included in the study; 20 were disregarded for not accepting to participate in the research. 18 patients did not meet the inclusion criteria - five minors, seven on peritoneal dialysis and six diagnosed with acute kidney disease. Six patients were also excluded because they had difficulty understanding the questions of the instruments. This difficulty was observed during the interview when they were unable to answer them clearly, even after the help of the interviewer or when they answered, several times, to something that was not related to what was being asked. Four were also excluded for having severe hearing or speech problems reported by the care team; four because they are occasionally undergoing hemodialysis in the services, because they are out on the town, traveling or another need and three due to the worsening of their health condition with displacement to another care unit.

Data collection, carried out by the researchers, took place with individual interviews during the hemodialysis sessions with the assistance of five nursing students and two pharmacy students trained for this purpose. Data was 
not collected from medical records. Sociodemographic and clinical questionnaires were used, as well as the Kidney Disease and Quality of Life Short-Form (KDQOL$\mathrm{SF}^{\mathrm{TM}}$ ), Back Depression Inventory (BDI) and Morisky Medication Adherence Scale - eight items.

The sociodemographic and clinical questionnaire comprised the following variables: age; gender; marital status; children; educational status; revenue; comorbidities; comorbidities, complications of kidney disease and intercurrences during and after hemodialysis. Among the comorbidities, the presence or absence of Systemic Arterial Hypertension (SAH) and Diabetes Mellitus (DM) for those being the main causes for the CKD in the world(3).

The KDQOL-SF ${ }^{\mathrm{TM}}$ is an instrument validated in Brazil that includes 80 items, the Short Form Health Survey (SF-36) and 43 more items on CKD. The SF-36 is divided into eight dimensions: physical functioning (ten items); limitations caused by physical health problems (four items); limitations caused by emotional health problems (three items); social functioning (two items); mental health (five items); pain (two items); vitality (four items); perceptions of general health (five items) and current health status compared to one year ago (one item). The items related to kidney disease are divided into 11 dimensions: symptoms/problems (12 items); effects of kidney disease on daily life (eight items); overload imposed by kidney disease (four items); working condition (two items); cognitive function (three items); quality of social interactions (three items); sexual function (two items); sleep (four items); social support scale (two items); dialysis team stimulation scale (two items) and patient satisfaction scale (one item). Another dimension comprises an item containing a scale from zero to ten for the assessment of health in general. The scores for each dimension range from zero to 100: being higher the score the better is the HRQoL ${ }^{(22)}$. The instrument also summarizes the score of the physical and mental component; the score of the first one derived from the items physical functioning, physical function, pain and general health and the second of the items vitality, social function, emotional role and mental health.

The BDI, validated in Portuguese and already used for the assessment of chronic kidney patients, consists of 21 items that include cognitive-affective, somatic aspects, guilt, life satisfaction, sleep disorders and health problems due to depression ${ }^{(23)}$. Each item is scored from zero to three: less than ten means no depression; ten to 18 , indicative of mild depression; 19 to 29 , moderate; 30 to 63 , severe depression.

The Morisky Medication Adherence Scale - eight items was validated and adapted to Brazil and assesses the patient's behavior regarding the usual drug use. It consists of seven questions with closed answers of a dichotomous yes/no character and the last question answered based on the options "never", "almost never", "sometimes", "often" and "always". Low adherence is considered to be those who answer affirmatively to more items from the test ${ }^{(24)}$.

The application of data collection instruments during the hemodialysis, although extensive, was not perceived by patients as uncomfortable, as the interview, as a form of interpersonal relationship, favored the perception that time in the dialysis unit passed more quickly.

For the operationalization of the analysis, the KDQOL-SFTM data were inserted in a spreadsheet of the program Excel for Windows provided on-line by the RAND Health Care (https://www.rand.org/healthcare/surveys_tools/kdqol.html), which automatically calculates scores by items and dimensions of the entire instrument. As this instrument does not have a cut-off point, the mean being displayed by the patients was used to be able to compare it with the results of other studies, which have also been using mean values.

The KDQOL-SFTM together with sociodemographic, clinical data, BDI scores and the Morisky Medication Adherence Scale - eight items constituted a database in another Excel spreadsheet that, transposed to the Statistical Package for the Social Sciences (SPSS), version 21.0, were analyzed. Descriptive analysis was used with calculation of mean, standard deviation, median, minimum, maximum and interquartile range. Absolute and relative frequencies were also used. Joint frequency distributions were also performed and two study variables were simultaneously observed in order to identify a relationship between them using the chi-square test. A significance level of 0.05 was considered.

All ethical aspects that govern research with people have been respected. The research was approved by the Ethics Committee on December 16, 2016 under opinion No. 1,871,846 and CAAE: 62565316.6/0000.5322 were observed.

\section{Results}

Of the 183 patients, 101 (55.2\%) were 60 years of age or older, $116(63.4 \%)$ were male, 119 (65.0\%) lived with a partner, $159(86.9 \%)$, with children, 147 $(80.3 \%)$ had low education and 166 (90.7\%) were retired. Regarding the clinical aspects, in addition to the CKD, it was found that $68(37.2 \%)$ had SAH and DM concomitantly; the others, one or another comorbidity and $111(60.7 \%)$ had indications of depression, as can be checked in Table 1. 
Table 1 - Prevalence of indications of depression and comorbidities in chronic kidney patients during hemodialysis sessions ( $n=183$ ). Ijuí, RS, Brazil, 2017

\begin{tabular}{lc}
\hline Variables & Number of patients (\%) \\
\hline Indications of depression & $111(60.7)$ \\
Absence of depression & $72(39.3)$ \\
Mild depression & $67(36.6)$ \\
Moderate depression & $41(22.4)$ \\
Severe depression & $3(1.6)$ \\
Comorbidity & \\
Hypertension and Diabetes Mellitus & $68(37.2)$ \\
Hypertension & $64(35.0)$ \\
Diabetes Mellitus & $21(11.5)$ \\
Others & $9(4.9)$ \\
Absence & $21(11.5)$ \\
\hline
\end{tabular}

Remark: There was more than one response per participant

Table 2 shows the complications of patients related to CKD, intercurrences during and after hemodialysis and adherence to drug therapy. It is evident that, among complications, anemia was the most common in 127 patients $(69.4 \%)$, followed by edema and cramps. During hemodialysis, hypotension and cramps were the most frequent intercurrences in $53.6 \%$ and $49.7 \%$ of patients, respectively. After the end of the session, $49.1 \%$ of the patients reported weakness; however, $28.4 \%$ mentioned the absence of symptoms.

Table 3 shows the mean scores of the HRQoL dimensions, minimum and maximum values. It appears that the worst scores are related to the dimensions Work status (19.40), Limitations due to physical problems
(22.54) and Overload imposed by kidney disease (42.66). It is identified that the patients had a mean physical component (35.38) lower than the mental component (48.10). The general average of HRQoL was 62.61.

Table 2 - Complications of kidney disease previously reported by patients and intercurrences during and after hemodialysis sessions ( $n=183$ ). Ijuí, RS, Brazil, 2017

\begin{tabular}{ll}
\hline Complications and intercurrences & Number of patients (\%) \\
\hline Kidney disease complications & $127(69.4)$ \\
Anemia & $110(60.1)$ \\
Edema & $96(52.5)$ \\
Cramp & $82(44.8)$ \\
Weakness & $76(41.5)$ \\
Pain & $59(32.2)$ \\
Cephalgia & $43(23.5)$ \\
Itching & $38(20.8)$ \\
Hypotension & $28(15.3)$ \\
Repetitive infections & \\
Complications during hemodialysis & $98(53.6)$ \\
Hypotension & $91(49.7)$ \\
Cramp & $20(10.9)$ \\
Pain & \\
Intercurrences after hemodialysis & $91(22.4)$ \\
Weakness & $52(28.4)$ \\
Absence of symptoms & $43(23.5)$ \\
Hypotension & $41)$ \\
\hline
\end{tabular}

Remark: There was more than one response per participant

Table 3 - Mean scores for the dimensions of quality of life related to the health of patients on hemodialysis. Ijuí, RS, Brazil, 2017

\begin{tabular}{|c|c|c|c|c|c|c|}
\hline Dimensions & Mean & Standard Deviation & Median & Minimum & Maximum & Amplitude and Interquartile \\
\hline $\begin{array}{l}\text { Dialysis team } \\
\text { support }\end{array}$ & 88.93 & 19.53 & 100 & 0 & 100 & 100 \\
\hline Sexual function & 84.24 & 24.41 & 100 & 0 & 100 & 100 \\
\hline Cognitive function & 83.42 & 17.73 & 86.67 & 20 & 100 & 80 \\
\hline $\begin{array}{l}\text { Quality of social } \\
\text { interaction }\end{array}$ & 81.75 & 18.26 & 86.67 & 20 & 100 & 80 \\
\hline Social support & 80.69 & 26.27 & 83.33 & 0 & 100 & 100 \\
\hline Physical problems & 75.35 & 16.48 & 79.17 & 16.67 & 100 & 83.33 \\
\hline $\begin{array}{l}\text { Effects of the } \\
\text { disease }\end{array}$ & 70.98 & 20.11 & 75.00 & 9.38 & 100 & 90.62 \\
\hline Patient satisfaction & 68.85 & 19.01 & 66.67 & 33.33 & 100 & 66.67 \\
\hline Sleep quality & 68.12 & 23.05 & 72.50 & 0 & 100 & 100 \\
\hline Emotional wellbeing & 68.09 & 24.74 & 76.00 & 4 & 100 & 96 \\
\hline Social role & 67.08 & 28.69 & 75.00 & 0 & 100 & 100 \\
\hline Pain & 64.81 & 30.70 & 67.5 & 0 & 100 & 100 \\
\hline Global health. & 61.69 & 22.50 & 60.00 & 0 & 100 & 100 \\
\hline Vitality & 57.38 & 23.24 & 60 & 0 & 100 & 100 \\
\hline General health & 53.58 & 23.48 & 50.00 & 5 & 100 & 95 \\
\hline
\end{tabular}


Table 3 - (continuation)

\begin{tabular}{|c|c|c|c|c|c|c|}
\hline Dimensions & Mean & Standard Deviation & Median & Minimum & Maximum & Amplitude and Interquartile \\
\hline $\begin{array}{l}\text { Limitations due to } \\
\text { emotional problems }\end{array}$ & 48.99 & 42.77 & 33.33 & 0 & 100 & 100 \\
\hline Functional capacity & 43.74 & 29.53 & 40 & 0 & 100 & 100 \\
\hline $\begin{array}{l}\text { Overload due to } \\
\text { kidney disease }\end{array}$ & 42.66 & 27.26 & 37.50 & 0 & 100 & 100 \\
\hline $\begin{array}{l}\text { Limitations due to } \\
\text { physical problems }\end{array}$ & 22.54 & 33.77 & 0 & 0 & 100 & 100 \\
\hline Work situation & 19.40 & 29.05 & 0 & 0 & 100 & 100 \\
\hline \multicolumn{7}{|c|}{ Summary of scores for the mental and physical component } \\
\hline Mental component & 48.10 & 11.35 & 48.8 & 19.12 & 67.48 & 48.36 \\
\hline Physical component & 35.38 & 8.85 & 35.13 & 15.91 & 59.11 & 43.20 \\
\hline
\end{tabular}

Figure 1 shows only sociodemographic variables, comorbidities and medication adherence significantly associated with scores below the general mean of HRQoL. It appears that sex and education are associated with the lowest means in a greater number of dimensions of HRQoL when compared with the other sociodemographic variables. Patients with symptoms of depression had lower means in all dimensions, except patient satisfaction.

Still in relation to the data contained in Figure 1, it appears that DM was correlated with more domains of HRQOL compared to SAH. In relation to medication adherence, an association was identified with half of the domains and mental component.
Sequentially, Figure 2 shows a significant association between complications of CKD, intercurrences during and after hemodialysis with scores below the mean in the dimensions of HRQoL. Among the complications, it is noted that repetitive infections negatively impact a greater number of dimensions (12) and mental component, followed by edema (eight dimensions and mental component).

Still in Figure 2, among the intercurrences after hemodialysis, the weakness was related to the 12 dimensions of HRQOL and the physical component. The absence of symptoms was shown to be a protective factor and was associated with eight dimensions and physical and mental components.

\begin{tabular}{|c|c|}
\hline Variables & Below the mean quality of life dimensions \\
\hline \multicolumn{2}{|c|}{ Characteristics of patients } \\
\hline Age & Limitations due to emotional problems, Mental component \\
\hline Marital Status & Work situation, Sexual function, Physical component \\
\hline Gender & Limitations due to emotional problems, Cognitive function, Sexual function, Functional capacity, Mental component \\
\hline Schooling & Social function, Cognitive function, Sexual function, Sleep quality \\
\hline Income & Quality of social interaction, Quality of sleep \\
\hline \multicolumn{2}{|l|}{ Comorbidities } \\
\hline Depression & $\begin{array}{l}\text { Effects of disease, Kidney disease burden, Quality of social interaction, Social support, Dialysis team support, Global health, } \\
\text { Emotional well-being, Limitations due to emotional problems, Social function, Physical problems, Work situation, Cognitive } \\
\text { function, Function sexual, Sleep quality, Functional capacity, Limitations due to physical problems, Pain, General health, Vitality, } \\
\text { Mental component, Physical component }\end{array}$ \\
\hline Hypertension & Work situation, Pain \\
\hline $\begin{array}{l}\text { Diabetes } \\
\text { Mellitus }\end{array}$ & Sexual function, General health, Vitality, Functional capacity, Physical component \\
\hline Drug adherence & $\begin{array}{l}\text { Effects of the disease, Kidney disease overload, Quality of social interaction, Limitations due to emotional problems, Social } \\
\text { function, Physical problems, Cognitive function, Limitations due to physical problems, General health, Vitality, Mental component }\end{array}$ \\
\hline
\end{tabular}

Remark: Association verified by chi-square test with $\mathrm{p} \leq 0.05$

Figure 1 - Sociodemographic variables, comorbidities and medication adherence significantly associated with scores below the mean in the dimensions of quality of life presented by patients on hemodialysis. Ijuí, RS, Brazil, 2017 


\begin{tabular}{|c|c|}
\hline Variables & Below the mean quality of life dimensions \\
\hline \multicolumn{2}{|c|}{ Kidney disease complications } \\
\hline Cramp & Limitations due to emotional problems, Physical problems, Limitations due to physical problems \\
\hline Cephalgia & Emotional well-being, Social function, Physical problems, Cognitive function, Functional capacity, Vitality, Mental component \\
\hline Itching & Quality of social interaction, Physical problems \\
\hline Hypotension & Effects of the disease, Physical problems, Work situation \\
\hline Weakness & Quality of social interaction, Dialysis team support, Global health, Functional capacity, Limitations due to physical problems, Vitality \\
\hline Pain & Effects of the disease, Physical problems, Work situation, Functional capacity, Pain, Vitality, Physical component \\
\hline $\begin{array}{l}\text { Repetitive } \\
\text { infections }\end{array}$ & $\begin{array}{l}\text { Effects of the disease, Kidney disease overload, Dialysis team support, Patient satisfaction, Emotional well-being, Limitations due to } \\
\text { emotional problems, Social function, Physical problems, Sleep quality, Limitations due to physical problems, Pain, Health in general, } \\
\text { Mental component }\end{array}$ \\
\hline Anemia & $\begin{array}{l}\text { Emotional well-being, Limitations due to emotional problems, Social function, Work situation, Limitations due to physical problems, } \\
\text { Vitality, Mental component }\end{array}$ \\
\hline Edema & $\begin{array}{l}\text { Overload of kidney disease, Quality of social interaction, Emotional well-being, Social function, Work situation, Cognitive function, } \\
\text { Sleep quality, Functional capacity, Mental component }\end{array}$ \\
\hline \multicolumn{2}{|c|}{ Intercurrences during hemodialysis } \\
\hline Cramp & Limitations due to physical problems, Pain, Health in general \\
\hline Pain & Kidney disease overload, Physical problems, Functional capacity, Limitations due to physical problems, Vitality \\
\hline \multicolumn{2}{|c|}{ Intercurrences after hemodialysis } \\
\hline Weakness & $\begin{array}{l}\text { Effects of disease, Kidney disease overload, Global health, Emotional well-being, Limitations due to emotional problems, Social } \\
\text { function, Physical problems, Cognitive function, Functional capacity, Limitations due to physical problems, Pain, Vitality, Mental } \\
\text { component, Physical component }\end{array}$ \\
\hline Hypotension & Limitations due to physical problems \\
\hline Nauseas & $\begin{array}{l}\text { Effects of the disease, Overload of kidney disease, Limitations due to emotional problems, Physical problems, Sleep quality, } \\
\text { Functional capacity, Pain, Vitality, Mental component }\end{array}$ \\
\hline $\begin{array}{l}\text { Absence of } \\
\text { symptoms }\end{array}$ & $\begin{array}{l}\text { Global health, Emotional well-being, Limitations due to emotional problems, Physical problems, Work situation, Functional capacity, } \\
\text { Limitations due to physical problems, Vitality, Mental component, Physical component }\end{array}$ \\
\hline
\end{tabular}

Remark: Association verified by chi-square test with $\mathrm{p} \leq 0.05$

Figure 2 - Complications of kidney disease, intercurrences during and after hemodialysis and absence of symptoms significantly associated with values below the mean in the dimensions of quality of life presented by patients on hemodialysis. Ijuí, RS, Brazil, 2017

\section{Discussion}

Among the main findings of this study, the HRQoL perceived as regular by the patients stands out; depression, weakness after hemodialysis and complications related to CKD, particularly repetitive infections and edema, as factors that compromise a greater number of dimensions of quality of life and the important impact of medication adherence and the absence of symptoms in several domains. These results help to reduce the existing knowledge gap on the subject.

HRQoL shows low scores in the dimensions Work situation, Physical problems, Overload imposed by the disease, Functional capacity, Physical component and Mental component, higher value referring to the support of the dialysis team, similar to the results of a study in Portugal(25). These data reveal that the well-being of patients on hemodialysis is compromised due to the physical, psycho-emotional state and the difficulties in maintaining a job and that support is an important tool to face this condition.

Regarding the indications of depression, more than half of the patients had symptoms, which is in line with the results of a study in India(26). Depressive disorders in this population can be related to the worst clinical outcomes, comorbidities, complications of the disease and treatment, hospitalizations, increased length of hospital stay, abandonment of dialysis, mortality and reduced quality of life $\mathrm{e}^{(9,27)}$.

In this investigation, indications of depression were associated with reduced scores in all dimensions of HRQoL, except patient's satisfaction. A study in Egypt showed a similar result, except for the domain Limitations due to physical problems ${ }^{(28)}$. Despite the link between depression and unfavorable outcomes, a minority of the patients is adequately diagnosed and this situation may be due to the overlap of symptoms associated with uremia(7). Measures aimed at reducing depressive symptoms become essential, including educational and problem-solving measures that can be developed by nursing professionals, including in dialysis units.

With regard to CKD complications, anemia, edema and cramps were reported by a greater percentage of patients; however, repetitive infections, edema, headache and anemia compromised a greater number of dimensions for the HRQoL. Similarly, research in Spain identified a negative relationship between somatic symptoms and quality of life, which 
are considered negative predictors of the physical and mental components(14).

Infections increase the risk of hospitalization and are common in renal patients. A study in the United States found a crude infection incidence rate of 23.6 per thousand person/year, a higher number associated with lower glomerular filtration rates or a high urinary albumin/creatinine ratio, also related to the increased risk of mortality ${ }^{(29)}$. Both hospitalizations and infections decrease HRQOL and their management can be done with health-promoting, preventive and curative interventions.

As for edema, research in the United Kingdom has shown an association between chronic edema and quality of life, which is particularly reduced in terms of physical and emotional capacity and health in general(30). It is considered that educational activities that favor self-care can positively impact the reduction of edema and improve HRQoL.

Pain is a common symptom among hemodialysis patients. In this research, a higher frequency of headache type was evidenced. In this sense, research in Western Pennsylvania found a painful sensation in $79 \%$ of patients, inversely linked to the Physical, mental components and global quality of life score ${ }^{(15)}$. During the dialysis session, the submitted data show that pain was related to physical, psycho-emotional and functional dimensions. A study in Greece showed cramping pain $(61.2 \%)$ and headache $(54.9 \%)$ during the session and point out that the subject's selfefficacy in chronic pain conditions is impaired, with less efficient control of the painful sensation(31).

Among the results, anemia also appeared as a common complication of CKD Iranian research found prevalence of anemia in $28.3 \%$ of the patients, $3 \%$ with hemoglobin levels below $8 \mathrm{~g} / \mathrm{dl}^{(32)}$. Multicentric research, in Brazil, France, Japan and Germany, showed a worsening in the quality of life according to the severity of the anemia and indicated an association of this complication with the progression of kidney disease and mortality(16). Data suggest that the adequate treatment of anemia, together with interventions that improve gastrointestinal symptoms and encourage compliance with the diet, and the provision of nursing care to prevent blood loss in hemodialysis may decrease the risk of this complication and its consequences.

Cramps, both as a complication of CKD and as a complication during hemodialysis, were reported as frequent by patients, with involvement of the lower limbs, hands and abdomen hypovolemia, hypomagnesemia, carnitine deficiency and elevated serum leptin levels appear to be involved in the event ${ }^{(17)}$.
In this sense, research in Greece demonstrated an association between cramps and limitations due to physical problems, pain, general health and interpersonal relationships ${ }^{(31)}$. It is considered that the proper identification and management of this complication is a patient's right and must integrate nursing care.

During the dialysis session, another prevalent complication was hypotension. Research in the Netherlands found a link between hypotension, increased cardiovascular morbidity and mortality and presence in more than half of dialysis sessions. The authors also revealed that patients with hypotension had lower pre-dialysis heart rates, low body weight and no residual renal function(18).

After dialysis, the weakness was associated with the greater number of dimensions of HRQOL and may be linked to the waste of protein energy and low physical activity ${ }^{(33)}$. A study in England and Ireland evaluated the presence of symptoms and identified that just $3 \%$ of the patients did not have symptoms. There was a predominance of weakness in $78.0 \%$ of the patients, difficulty in movement in $66.0 \%$ and pain in 64\%, all independently associated with a worse quality of life ${ }^{(19)}$. It is assessed that the weakness interferes with the recovery time after dialysis, the return to daily activities and, in this context, the recognition of the etiology by the health professional and the implementation of prevention and care actions can improve the patient's conditions.

In relation to the absence of symptoms after dialysis, the results of this research showed it as a protective factor with influence in several domains of HRQoL, particularly in the Work Situation, Global Health, Functional Capacity, Limitation due to physical and emotional problems, Vitality, Well -Emotional being, Physical and mental components. This result reinforces the importance of Nursing and the multidisciplinary team to work to prevent, identify and reduce intercurrences(34).

Adherence to drug therapy also had an impact on the HRQoL of patients evaluated in this research and was associated with the lowest mean scores related to the burden imposed by kidney disease, Effects of the disease, Quality of social interaction, Cognitive function, Health in general, Limitations due to emotional problems and physical, social function, vitality and mental component. Research in Iran has shown a significant positive relationship between treatment adherence and the overall quality of life score, as well as with all its dimensions. The authors emphasized the need for personalized educational interventions in order to sensitize the patient about 
his condition and the importance of adherence to treatment ${ }^{(35)}$. It is inferred that not using the medication properly increases the perception of the symptoms of the disease and the occurrence of damage to physical, psycho-emotional and social well-being.

As for the presence of comorbidities, a higher percentage of patients with arterial hypertension and diabetes was identified, concomitantly or with only one. The first was related to lower scores in the dimensions Work status and Pain; the second was associated with Vitality, Health in general, Functional capacity, Sexual function and Physical component. These diseases are considered the main causes of $\mathrm{CKD}^{(3)}$ and, regarding HRQoL, both negatively affect it ${ }^{(13)}$. It appears that having one or more diseases simultaneously increases the burden of physical, psycho-emotional symptoms and necessary care, which results in greater limitations, with a consequent worsening in the quality of life and evolution of the disease.

In the investigated patients, the sociodemographic profile is similar to that of research in São Paulo, except for age ${ }^{(36)}$. Regarding the association between HRQoL and sociodemographic characteristics, the age of less than 60 years had a lower score in the aspects Limitations due to emotional problems and Mental component, similar to an Australian study ${ }^{(10)}$. It is believed that the elderly have better adaptability or maturity to deal with the disease, respond better to stressors, which favors a more positive perception of HRQoL compared to younger people in the face of the CKD.

Regarding gender, women had lower scores on Cognitive Function, Sexual Function, Functional Capacity and Mental Component, similarly to the investigation in Turkey, which identified a reduced score in women regarding Symptoms, Effects of the disease and Physical and mental components(11). The results of this research may be related to the lower percentage of muscle mass in women compared to men, which is linked to functional capacity. Likewise, there is evidence that decreased functional capacity has a worse cognitive performance ${ }^{(37)}$, which can be prevented or improved with physical activity. Impaired sexual function can be linked to aging, climacteric and the taboos that still exist regarding sex. Regarding the score of the mental component, it can be attributed to the reduction of estrogen levels in female aging that favor emotional changes and cultural values related to gender.

As for marital status, having a partner was associated with the worst scores in the dimension Work Situation, Physical Component and Sexual Function. A Brazilian study also showed less satisfaction in sexual function in individuals with a fixed partner ${ }^{(37)}$ in disagreement with another investigation, also Brazilian, which showed the partner as a synonym for greater social support( ${ }^{(38)}$. It is inferred that patients with a partner feel supported to face the disease, however, they feel dependent on the partner in relation to the financial situation and would like to be in a better physical state to perform activities, including those related to the marital role.

Low schooling reflected in lower scores for cognitive function, quality of sleep, sexual function and social function. In this sense, a study in Brazil found that patients with a higher level of education (complete elementary school or more) had higher scores in several domains of HRQoL, while those with incomplete elementary school had a 4.3 times greater chance of impairment in social function ${ }^{(12)}$. Thus, it is understood that individuals with low education have little access to information and the ability to properly understand traumatic events, which can translate into greater concern, anxiety, insomnia and decrease their energy for other activities.

Income from retirement in CKD patients was linked to reduced quality of sleep and social interaction. On the other hand, research in Nepal showed that higher income was related to high scores in the Psychological, Environmental and Health domains in general(39). It is suggested that people with less financial resources experience difficulties in coping with the costs of the disease, limiting their spending, including on leisure, which can interfere with sleep patterns and social interaction.

Assessing the HRQoL in patients with CKD undergoing hemodialysis is a complex task in view of the multiple factors involved in its perception and the difficulty to fully address it. However, the assessment of HRQoL favors the identification of the subjects' needs for planning aimed at coping with the disease. In this sense, Nursing as a profession that requires direct contact with the patient must be able to identify factors that affect the quality of life of these patients, as well as to develop activities capable of reducing symptoms, improving physical and mental capacity, promoting self-care, that assist patients in adapting and coping with problems.

The results presented and discussed in this investigation contribute to the advancement of scientific knowledge by reducing gaps in the association between HRQoL with complications of kidney disease, intercurrences during and after hemodialysis and adherence to drug therapy in patients with CKD and by pointing out the potentially modifiable factors that reduce $\mathrm{HRQOL}$ and are able to be identified by professionals from the multiprofessional team, 
especially from Nursing, at the same time that they can become the focus of attention and care in order to promote health and well-being.

As a limitation of this research one highlights the methodology of the cross-sectional study, which allows only a specific perception of the patient's conditions, although it is useful to identify needs and encourage the implementation of improvement interventions.

\section{Conclusion}

The reduced HRQoL in chronic renal patients undergoing hemodialysis is associated, mainly, with depressive symptoms, complications of the disease such as repetitive infections, headache, pain and anemia, weakness after a dialysis session and low adherence to drug therapy. It was evident how much these factors interfere in the patients' adaptation and that they can be modified, as long as the team responsible for care assumes this commitment. The effectiveness of this care can occur from the assessment of the conditions of the patients, planning and adequacy of dialysis, conventional, integrative or complementary interventions aimed at health, empowerment, self-care, physical improvement and psycho-emotional well-being. In relation to the public health, the appropriation of this knowledge can, positively, impact the development of policies and actions aimed at improving the quality of life of this population.

\section{References}

1. Roth GA, Abate D, Abate KH, Abay SM, Abbafati C, Abbasi N, et al. Global, regional, and national incidence, prevalence, and years lived with disability for 354 diseases and injuries for 195 countries and territories, 1990-2017: a systematic analysis for the Global Burden of Disease Study 2017. Lancet. 2018 Nov 10;392:1789-858. doi: https://doi.org/10.1016/ S0140-6736(18)32279-7

2. Thomé FS, Sesso RC, Lopes AA, Lugon JR, Martins CT. Brazilian chronic dialysis survey 2017. J Bras Nefrol. 2019 Mar;41(2):208-14. doi: http://dx.doi. org/10.1590/2175-8239-jbn-2018-0178

3. Webster AC, Nagler E, Morton RL, Masson P. Chronic Kidney Disease. Lancet. 2017 Mar 25;389(10075):1238-52. doi: http://dx.doi. org/10.1016/ S0140-6736(16)32064-5

4. Hill NR, Fatoba ST, Oke JL, Hirst JA, O'Callaghan CA, Lasserson DS, et al. Global Prevalence of Chronic Kidney Disease - A Systematic Review and MetaAnalysis. PLoS One. 2016 Jul 6;11(7):e0158765. doi: 10.1371/journal.pone.0158765. PMID: 27383068; PMCID: PMC4934905
5. Cruz VFES, Tagliamento G, Wanderbroocke AC. The maintenance of work life by chronic kidney patients in hemodialysis treatment: an analysis of the meanings of work. Saúde Soc. [Internet]. 2016 [Cited Mar 6, 2020];25(4):1050-63. Available from: http:// www.scielo.br/pdf/sausoc/v25n4/1984-0470sausoc-25-04-01050.pdf

6. Lopes CF, Queiroga FCG, Fonseca VMB, Ferreira TS, Dourado AM, Lages $A L$, et al. Concept and instruments for assessing the quality of life and health. REAS. 2018;1(Supl 11):1076-80. doi:10.25248/ REAS137_2018

7. Shirazian S, Grant CD, Aina O, Mattana J, Khorassani F, Ricardo AC. Depression in Chronic Kidney Disease and End-Stage Renal Disease: Similarities and Differences in Diagnosis, Epidemiology, and Management. Kidney Int Rep. 2016 Sep 20;2(1):94-107. doi: 10.1016/j. ekir.2016.09.005

8. Chan R, Dear BF, Titov N, Chow J, Suranyi M. Examining internet-delivered cognitive behaviour therapy for patients. J Psychosom Res. 2016 Oct; 89: 78-84. doi:10.1016/j.jpsy chores.2016.08.012

9. Ganu VJ, Boima V, Adjei DN, Yendork JS, Dey ID, Yorke $E$, et al. Depression and quality of life in patients on long term hemodialysis at a national hospital in Ghana: a cross-sectional study. Ghana Med J. 2018 Mar;52(1):22-8. doi:10.4314/gmj.v52i1.5

10. Zimbudzi E, Lo C, Ranasinha S, Gallagher M, Fulcher $\mathrm{G}$, Kerr PG, et al. Predictors of health-related quality of life in patients with co-morbid diabetes and chronic kidney disease. PLoS One. 2016 Dec 19;11(12):e0168491. doi: 10.1371/journal.pone.0168491

11. Mollaoğlu M, Deveci G. Quality of Life in Patients with Chronic Renal Failure and Some Affecting Factors. Arch Renal Dis Manag. 2017 May;3(1):12-9. doi:10.17352/2455-5495.000020

12. Fukushima RLM, Menezes ALC, Inouye K, Pavarini SCI, Orlandi FS. Quality of life and associated factors in patients with chronic kidney disease on hemodialysis. Acta Paul Enferm. 2016 Oct;29(5):518-24. doi: 10.1590/1982-0194201600072

13. Porter AC, Lash JP, Xie D, Pan Q, DeLuca J, Kanthety $R$, et al. Predictors and outcomes of healthrelated quality of life in adults with CKD. Clin J Am Soc Nephrol. 2016 Jul;11(1):1154-62. doi: 10.2215/ CJN.09990915

14. Montilla CP, Duschek S, Paso GR. Healthrelated quality of life in chronic kidney disease: Predictive relevance of mood and somatic symptoms. Nefrología. 2016;36(3):275-82. doi: 10.1016/j. nefroe.2016.06.003

15. Belayev LY, Mor MK, Sevick MA, Shields AM, Rollman $\mathrm{BL}$, Palevsky $\mathrm{PM}$, et al. Longitudinal associations of 
depressive symptoms and pain with quality of life in patients receiving chronic hemodialysis. Hemodial Int. 2015 Apr;19(2):216-24. doi: 10.11 11/hdi.12247

16. Hoshino J, Muenz D, Zee J, Sukul N, Speyer E, Guedes $M$, et al. Associations of hemoglobin levels with health-related quality of life, physical activity, and clinical outcomes in persons with stage 3-5 nondialysis CKD. J Ren Nutr. 2019:1-11. doi: https:// doi.org/10.105 3/j.jrn.2019.11.003

17. Beladi Mousavi SS, Zeraati A, Moradi S, Mousavi $M B$. The effect of gabapentin on muscle cramps during hemodialysis: A double-blind clinical trial. Saudi J Kidney Dis Transpl. [Internet]. 2015 [Cited Jan 1, 2018];26:1142-8. Available from: http://www.sjkdt. org/text.asp?2015/26/6/1142/168588

18. Kuipers J, Oosterhuis JK, Krijnen WP, Dasselaar JJ, Gaillard CAJM, Westerhuis R, et al. Prevalence of intradialytic hypotension, clinical symptoms and nursing interventions - a three-months, prospective study of 3818 hemodialysis sessions. BMC Nephrol. 2016 Feb;17(21):2-11. doi: 10.1186/ s12882-016-0231-9 19. Lowney AC, Myles HT, Bristowe K, Lowney EL, Shepherd K, Murphy M, et al. Understanding what influences the health-related quality of life of hemodialysis patients: a collaborative study in England and Ireland. J Pain Symptom Manage. 2015 Dec;50(6):778-85. doi: 10.1016/j.jpainsymman.2015.07.010

20. Bossola M, Tazza L. Postdialysis Fatigue: A Frequent and Debilitating Symptom. Semin Dial. 2016 May-Jun;29(3):222-7. doi:10.1111/sdi.12468

21. Díaz-Soto CM, Présiga-Ríos PA, Zapata-Rueda CM. Quality of Life Related to Health and Adherence to Treatment in Patients with Chronic Kidney Disease in Antioquia-Colombia. Revista de Educación y Desarrollo. [Internet]. 2017 Apr/June [Cited Dec 6, 2017];41(1): 17-25. Available from: http://www.cucs.udg.mx/ revistas/edu_desarrollo/anteriores/41/41_Diaz. pdf 22. Duarte OS, Ciconelli RM, Sesso R. Cultural adaptation and validation of the "Kidney Disease and Quality of Life - Short Form (KDQOL-SF ${ }^{\mathrm{TM}} 1.3$ )" in Brazil. Braz J Med Biol Res. 2005 Feb;38(2):261-70. doi: 10.1590/S0100-879X2005000200015

23. Schuster JT, Feldens VP, Iser BPM, Ghislandi GM. Evaluation of depressive symptoms in patients with chronic kidney disease undergoing hemodialysis in Tubarão, SC, Brazil. Rev AMRIGS. 2015 Jan/ Mar;59(1):15-9. doi: 10.13140/RG.2.1.1638.9848

24. Okac E, Acar B, Kocaöz D. Medical adherence to intranasal corticosteroids in adult patients. Braz J Otorhinolaryngol. 2017;83(5):558-62. doi: 10.1016/j. bjorl.2016.06.007

25. Moura A, Madureira J, Alija P, Fernandes JC, Oliveira JG, Lopez M, et al. Predictors of health-related quality of life perceived by end-stage renal disease patients under online hemodiafiltration. Qual Life Res. 2015 Jun;24(1):1327-35. doi: 10.1007/s11136-0140854-x

26. Aggarwal HK, Jain D, Dabas G, Yadav R. Prevalence of depression, anxiety and insomnia in chronic kidney disease patients and their co-relation with the demographic variables. Prilozi. 2017;38(2):35-44. doi: https://doi.org/10.1515/prilozi-2017-0020

27. Goh ZS, Griva K. Anxiety and depression in patients with end-stage renal disease: impact and management challenges - a narrative review. Int J Nephrol Renovascular Dis. 2018 Mar;11:93-102. doi: 10.2147/IJNRD.S126615

28. Donia AF, Zaki NF, Elassy M, Elbahaey W. Study of depression and quality of life among hemodialysis patients: an Egyptian experience. Int Urol Nephrol. 2015 Nov;47(1):1855-62. doi: 10.1007/s11255-015-1091-0 29. Ishigami J, Grams ME, Chang AR, Carrero JJ, Coresh J, Matsushita K. CKD and risk for hospitalization with infection: The Atherosclerosis Risk in Communities (ARIC) Study. Am J Kidney Dis. 2017 Jun;69(6): 752-61. doi: 10.1053/j.ajkd.2016.09.018

30. Moffatt CJ, Aubeeluck A, Franks PJ, Doherty DC, Mortimer $\mathrm{P}$, Quere I. Psychological factors in chronic edema: a case-control study. Lymphat Res Biol. 2017 Sept;15(3):252-61. doi: 10.1089/Irb.2017.0022

31. Zyga S, Alikari V, Sachlas A, Stathoulis J, Aroni A, Theofilou $P$, et al. Management of pain and quality of life in patients with chronic kidney disease undergoing hemodialysis. Pain Manag Nurs. 2015 Oct;16(5): 712-20. doi: 10.1016/j.pmn.2015.03.004

32. Nafar M, Samavat S1, Khoshdel A, Alipour-Abedi B. Anemia evaluation and erythropoietin dose requirement among hemodialysis patients - a multicenter study. Ira J Kidney Dis. [Internet]. 2017 Jan [Cited Dec 6, 2017];11(1):56-65. Available from: http://www.ijkd. org/index.php/ijkd/article/view/3057/899

33. Souweine J-S, Kuster N, Chenine L, Rodriguez $A$, Patrier $L$, Morena $M$, et al. Physical inactivity and protein energy wasting play independent roles in muscle weakness in maintenance haemodialysis patients. PLoS One. 2018;13(8):e0200061. doi: https://doi.org/10.1371/journal.pone.0200061

34. Coitinho D, Benetti ERRB, Ubessi LD, Barbosa DA, Kirchner RM, Guido LA, et al. Complications in hemodialysis and health assessment of chronic renal patients. Av Enferm. 2015;33(3):362-71. doi: 10.15446/av.enferm.v33n3.38016

35. Rahdar $Z$, Jahantigh Haghighi M, Mansouri A, Siasary A, Alahyari J, Jahantigh F. Probing the Relationship Between Treatment Regimen Compliance and the Quality of Life in Hemodialysis Patients: 
A Descriptive-Analytic Study. Med Surg Nurs J. 2019;8(2):e95599. doi: 10.5812/msnj.95599

36. Berttoni LC, Ottaviani AC, Orlandi FS. Association between self-care and quality of life in chronic kidney disease patients. Rev Eletr Enf. 2017;19:a14. doi: $10.5216 /$ ree.v19.27442

37. Aristotelous $P$, Stefanakis M, Pantzaris M, Pattichis C, Hadjigeorgiou GM, Giannaki CD. Associations between functional capacity, isokinetic leg strength, sleep quality and cognitive function in multiple sclerosis patients: a cross-sectional study. Postgraduate Medicine. 2019 Oct;131(7):453-60. doi:10.1080/003 25481.2019.1662271

38. Costa GMA, Pinheiro MBGN, Medeiros SM, Costa RRO, Cossi MS. Quality of life of patients with chronic kidney disease undergoing hemodialysis. Enferm Glob. 2016 July;15(43):87-99. doi: 10.6018/ eglobal.15.3.213891

39. Joshi U, Subedi R, Poudel P, Ghimire PR, Panta S, Sigdel MR. Assessment of quality of life in patients undergoing hemodialysis using WHOQOLBREF questionnaire: a multicenter study. Int J Nephrol Renovasc Dis. 2017 Jul;10:195-20. doi: 10.21 47/ IJNRD.S136522 Creative Commons (CC BY).

This license lets others distribute, remix, tweak, and build upon your work, even commercially, as long as they credit you for the original creation. This is the most accommodating of licenses offered. Recommended for maximum dissemination and use of licensed materials. 